\title{
Synthesis of Peptides by Using Recombinant Proteins
}

Synthesis of thiol-linker-attached peptides as C-terminal building blocks from nonprotected peptides:

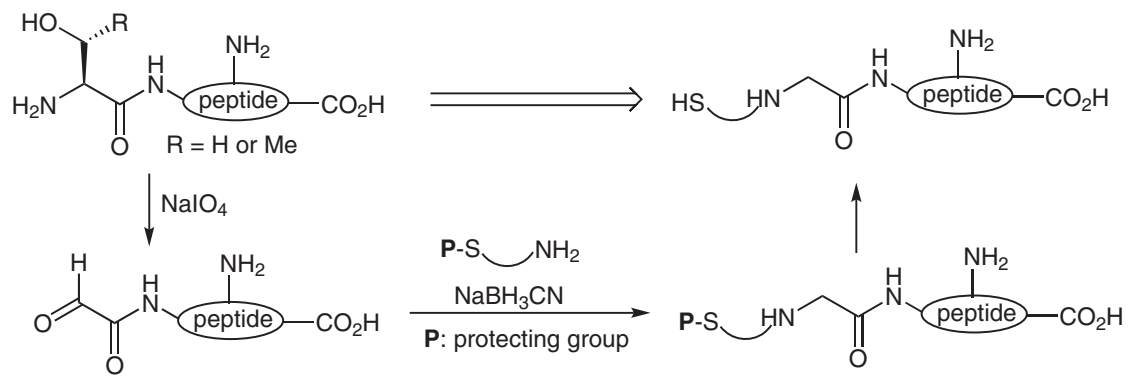

Peptide bond formation mediated by 4,5-dimethoxy-2-mercaptobenzylamine:

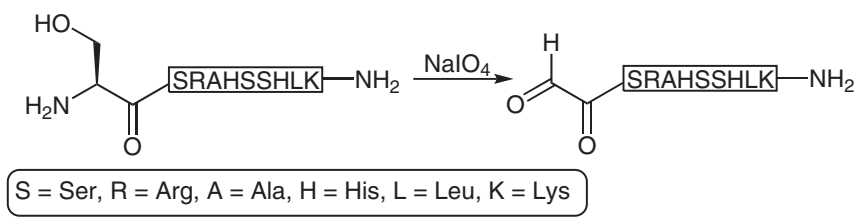

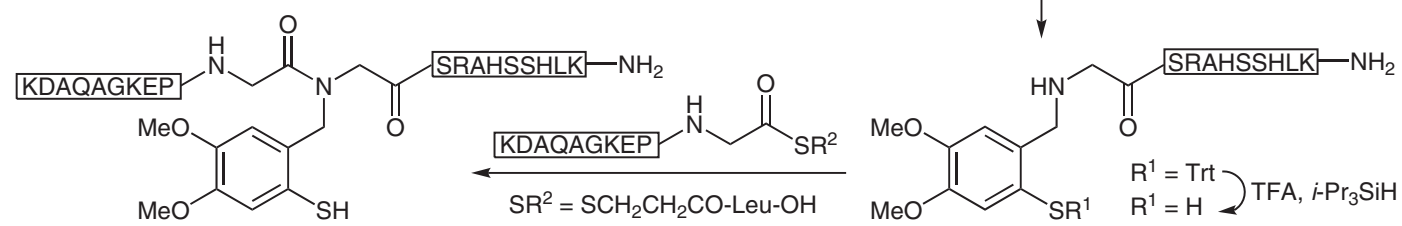

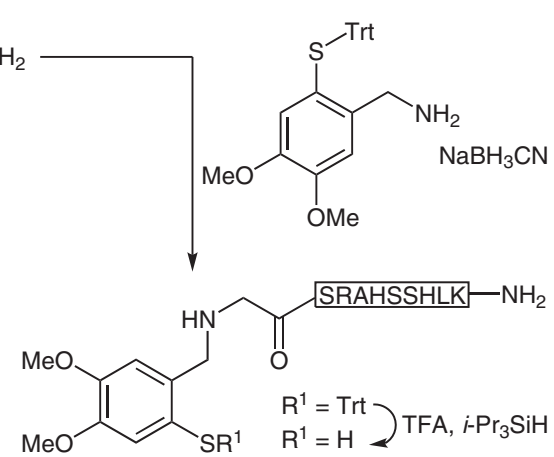

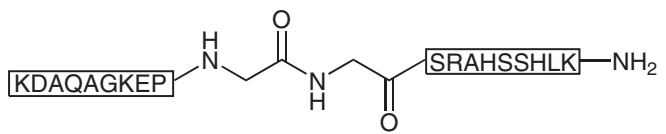

Significance: In 2001, Aimoto and co-workers reported an approach for the synthesis of polypeptides by using recombinant proteins in combination with peptide thioesters. A thiol-linker-attached peptide for condensation with the peptide thioester was successfully synthesized from a nonprotected peptide through periodate oxidation of an $\mathrm{N}$-terminal serine residue, followed by reductive amination with 4,5-dimethoxy-2-mercaptobenzylamine (Dmmb-NH $\mathrm{NH}_{2}$.
Comment: A N-2-mercaptobenzyl group on the backbone of a peptide is too stable under acidic conditions. The introduction of two methoxy groups on the benzene ring permitted the Dmmb group to be removed, after condensation, by treatment with $1 \mathrm{M} \mathrm{TfOH}$ in TFA. Instead of periodate oxidation of serine and threonine, transamination of $\mathrm{N}$-terminal amino groups could also be used in principle, although the stereochemistry resulting from the reductive amination should be controlled. 